\title{
Assessment of the Genotoxic Potential of Cizolirtine a Substance-P and Calcitonin Gene-Related Peptide Release Modulator
}

\author{
Authors \\ Antonio R. Fernández de Henestrosa®, Ana-Paz Marín, Araceli Tortajada, Cristina Vila, Antonio Guzmán
}

\author{
Affiliation \\ Department of Toxicology, ESTEVE Pharamaceuticals, \\ Spain \\ Key words \\ received $\quad 02.07 .2020$ \\ accepted $\quad 05.10 .2020$ \\ published online $\quad 04.11 .2020$ \\ Bibliography \\ Drug Res 2021; 71: 73-82 \\ DOI 10.1055/a-1286-5358 \\ ISSN 2194-9379 \\ (C) 2020. Thieme. All rights reserved. \\ Georg Thieme Verlag KG, Rüdigerstraße 14, \\ 70469 Stuttgart, Germany \\ Correspondence \\ Antonio R. Fernández de Henestrosa \\ Department of Toxicology \\ WELAB \\ Parc Científic Barcelona, C/Baldiri Reixac 4-8, \\ 08028 Barcelona, \\ Spain \\ Tel.: + 34629647918 \\ arodriguezf@welab.barcelona
} Barcelona and Department of Toxicology, WELAB, Barcelona,

genotoxic assessment, ames test, mouse lymphoma assay, chromosome aberrations assay, mouse in vivo micronuclei

\begin{abstract}
The analysis of the genotoxic potential of cizolirtine, a compound being developed as a drug for analgesia and for urinary incontinence, was carried out using a battery of in vitro and in vivo assays as recommended in the guidelines for medicinal products. Negative results were obtained in an Ames test (up to $5000 \mu \mathrm{g} /$ plate), in a Mouse Lymphoma assay (up to $2000 \mathrm{\mu g} / \mathrm{ml}$ ) and in a single dose mouse bone marrow micronucleus assay (up to $300 \mathrm{mg} / \mathrm{kg}$ ). In a human lymphocyte chromosome aberration assay, a slight statistical increase in the frequency of cells with chromosome aberrations including gaps was reported for the concentrations of 200 and $1600 \mu \mathrm{g} / \mathrm{ml}$ at the 24-h sampling time. This minor increase in chromosome aberrations was considered of questionable biological relevance since it was moderate, was within the laboratory historical control values, did no show a dose-dependent effect and was not observed at similar concentrations in a repeat assay. Taking into considerations the results obtained in the different in vitro and in vivo assays and a weight-of-evidence analysis, it suggests that cizolirtine would not pose a genotoxic risk when administered to humans.
\end{abstract}

\section{Introduction}

Cizolirtine $[( \pm)-5-\{\alpha-[2-(d i m e t h y l a m i n o) e t h o x y] b e n z y l\}-1-m e-$ thyl-1H-pyrazol citrate] ( $>$ Fig. 1 ) is a drug with a potent analgesic profile, that has shown its antinociceptive properties in several rodent models of acute pain. More precisely, cizolirtine is able to reduce in a dose-dependent manner the pain caused by chemical (i.p. injection of phenylbenzoquinone or acetic acid), thermal (tail-flick), or mechanical stimuli (tail-pinch). In a similar way, it prevents painassociated behaviors induced by intradermal injection of either formalin or capsaicin and is able to decrease thermal hyperalgesia evoked by subplantar injection of carrageenan [1,2]. Such results concur with data obtained in human volunteers, where cizolirtine decreased pain produced by thermal and electrical stimuli in a dose-related manner [3], and was found to mitigate the pain caused by third molar extraction [4]. Cizolirtine also showed its antinociceptive activity in animal models of chronic painful neuropathy, alleviating allodynia against cold and mechanical stimulations in rats that suffered sciatic nerve constriction $[3,5]$. In the same way, cizolirtine demonstrated to induce a dose-dependent antihyperalgesia in the streptozotocin (STZ)-induced diabetic neuropathy model [6]. These results are in line with the ones obtained in clinical trials, where significant reduction in pain effects of this drug in patients under conditions of posttraumatic/postherpetic neuropathy [7], cancer pain, and diabetic neuropathy [3] has been shown. 
Due to in vivo studies showing that cizolirtine significantly reduced the spinal release of substance $P$ and calcitonin gene-related peptide (CGRP) in both healthy and diabetic hyperalgesic rats, it has been attributed to this drug a role as a modulator of the release of these two neuropeptides involved in the transmission of nociceptive signals from the periphery to the central nervous system $[6,8]$. This modulation effect on substance-P and CGRP is likely linked to the increase of noradrenaline and serotonin levels at the extracellular space. The action of noradrenaline and serotonin on the noradrenergic pathway induces a decrease in the release of substance $P$ and CGRP at supraspinal level in the primary fibers $[2,6,8]$. These effects are the basis for its beneficial potential in the inflammation process of the urinary bladder, where visceral regulation of the motility would be facilitated by means of tachykinin control and therefore could be potentially favourable in certain forms of urinary incontinence [9].

Overactive bladder is a syndrome with high prevalence in both, women and men causing a negative impact on their quality of life $[10,11]$. Nowadays, a remarkable number of antimuscarinic drugs are marketed them being the first-line drug therapy for overactive bladder [12]. The efficacy of cizolirtine on overactive bladder has been shown at preclinical level in animal models. More precisely, in a model of increased intraluminal pressure in rats, cizolirtine is able to reduce the vesical contractions width without modifying their rhythm. Moreover, cizolirtine produces a clear effect on urodynamic function in a rat model of isovolumetric rhythmic bladder contractions. Yet, cizolirtine is active in protecting from the effects of the intrabladder infusion of acetic acid in rats, thus regularizing the micturition frequency and volume and the area under the curve of intravesical pressure related to time (Saenz de Tejada, 2005 umpublished results). In a phase II proof of concept clinical trial cizolirtine improved significantly bladder diary variables versus placebo: voidings number per $24 \mathrm{~h}$ were reduced, mean voided volume per voluntary micturition was increased and the number of patients achieving less than eight voidings per $24 \mathrm{~h}$ and/or complete dryness was also increased. Altogether, cizolirtine shows a promising

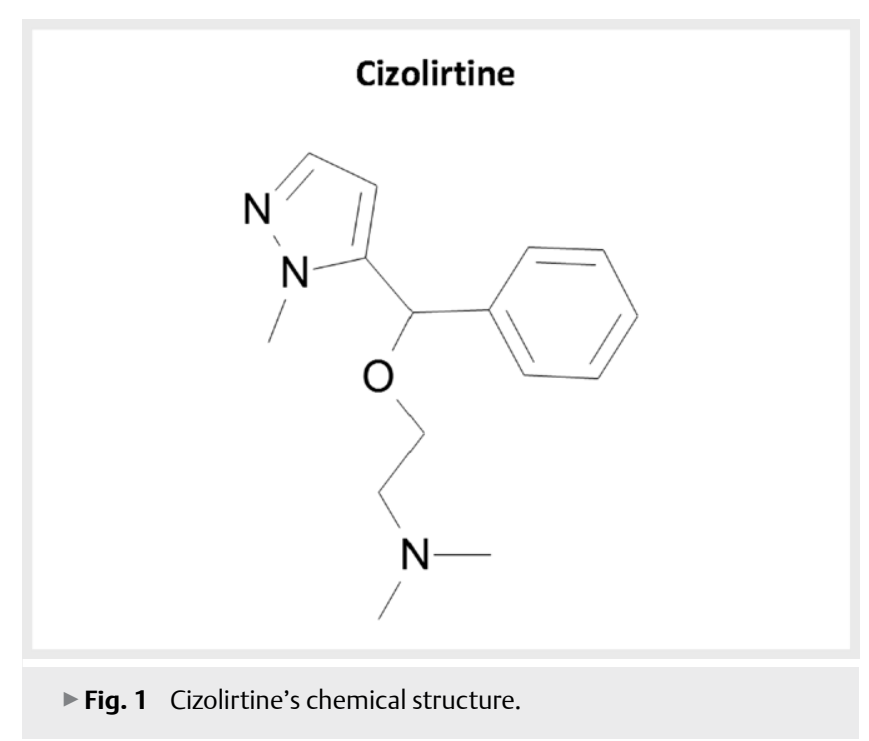

profile in the treatment of overactive bladder with urinary incontinence $[13,14]$.

In this publication we report the results of the battery of genotoxicity studies as recommended by regulatory authorities as part of the preclinical safety assessment program for the development of cizolirtine as a drug to alleviate the effects of the two above mentioned disease conditions.

\section{Material and Methods}

\section{Test substance}

Cizolirtine bulk powder was synthesized by ESTEVE (Barcelona, Spain) ( Fig. 1). Cizolirtine was administered as a citrate salt in all studies with purity always above $95.5 \%$. Test article solutions were prepared by dissolving cizolirtine in reverse-osmosis water immediately prior to the Ames Test and Mouse Lymphoma (ML) assays. For the Chromosome Aberration (CA) assay, the compound was dissolved in dimethyl sulfoxide (DMSO). Likewise, the solvent used in Mouse micronuclei assay was $0.9 \%$ saline solution. For in vitro studies, a stock solution was prepared at the maximum concentration required for the treatment and was diluted in appropriate sterile solvent to reach the required concentrations. The test material formulations were prepared as near as possible to the time of dosing. The vehicle (either, $0.9 \%$ saline solution, DMSO or reverse-osmosis water) was used as negative control for all studies. Positive control chemicals were obtained from the following manufacturers: cyclophosphamide (CP, Sigma), ethyl methanesulfonate (EMS, Sigma), methyl methanesulfonate (MMS, Sigma), 3-methylcholanthrene (3-MC, Sigma), 4-nitroquinoline 1-oxide (NQO, Sigma), 2-nitrofluorene (2NF, Aldrich), sodium azide ( $\mathrm{NaN}_{3}$, Sigma), 9-aminoacridine (AAC, Sigma), 2-aminoanthracene (AAN, Aldrich). $\mathrm{NaN}_{3}$ and $\mathrm{CP}$ were dissolved in water, while the remaining positive control chemicals were dissolved in DMSO.

\section{Metabolic activation system}

Mammalian liver post-mitochondrial faction (S9) was used for metabolic activation in all in vitro experiments. $\$ 9$ fractions were generated from the livers of male Sprague-Dawley (Ames Test and CA assay) or Fischer 344 (ML assay) rats induced with Aroclor 1254. S9 post-mitochondrial faction were purchased from Organon Teknika (CA), ICN Cappel (Ames Test) or Harlan UK (ML). Fractions were stored frozen at approximately $-80^{\circ} \mathrm{C}$. Just prior to use, fractions were thawed and supplemented with a NADPH-generating system. Final concentration of the $S 9$ fraction in the treatment medium for all in vitro assays was $10 \%$.

\section{Animal housing}

Animals that intervened in the in vivo micronuclei assay were housed in rooms set at target values of $22^{\circ} \mathrm{C}$ of temperature and $50 \%$ of relative humidity. On the other hand, lighting was controlled to give a $12 \mathrm{~h}$ light-dark cycle while the air conditions were guaranteed setting a minimum of 15 volume changes of air per hour. All procedures involving animals and their care were conducted in strict conformity with the European Community Guide for the Care and Use of Laboratory Animals [15]. 


\section{Ames test}

The method used was the described previously [16] following the recommendations of the corresponding OECD guideline [17]. Salmonella typhimurium TA98, TA100, TA1535, TA1537 (histidine auxotrophic strains) and Escherichia coli (WP2 uvrA pKM101) (auxotrophic for tryptophan) were conforming the panel of the study. The Salmonella strains were obtained from CECT (Spanish Type Culture Collection, Spain) while the E. coli strain was obtained from NCIBM Ltd (National Collection of Industrial Food and Marine Bacteria, UK). A frozen sample of each tester strain was thawed and grown in NB2 culture media until late-exponential culture phase.

Two independent experiments were conducted, both in the presence and in the absence of metabolic activation. Each concentration of test substance, or either positive or negative control, was tested in triplicate plates. Test concentrations and conditions are detailed in — Table 1. $2 \mathrm{NF}, \mathrm{NaN}_{3}, \mathrm{NQO}, \mathrm{AAC}$, and AAN were used as positive controls, and sterile reverse-osmosis water as vehicle control. Experiment 1 followed the plate-incorporation assay procedure whereas for Experiment 2, the preincubation method was used. Briefly, $0.1 \mathrm{ml}$ of test substance (or control solution), $0.1 \mathrm{ml}$ of bacterial culture and $0.5 \mathrm{ml}$ of $10 \% \mathrm{~S} 9 \mathrm{mix}$ (phosphate buffer solution for treatment without activation) were mixed and poured on to Vogel Bonner-E minimal agar plates after addition of $2 \mathrm{ml}$ of top agar at $42^{\circ} \mathrm{C}$. In the case of Experiment 2, this mix was incubated for $20 \mathrm{~min}$ at $37^{\circ} \mathrm{C}$, before addition of $2 \mathrm{ml}$ molten agar at $42^{\circ} \mathrm{C}$.

Plates were incubated at $37^{\circ} \mathrm{C}$ in the dark for $48-72 \mathrm{~h}$. After this period of time, revertant colonies were counted. In order to assess toxicity signs the background lawn was inspected and the potential decrease in the number of colonies compared to the negative control was also considered. From the individual plate counts the mean and standard deviation for each treatment were determined. The one-way of the variance [18] was used to compare counts of each test substance concentration with its corresponding vehicle control. The Duncan test was used in case significance was found. Statistical significance was not the only criteria to determine a positive response as biological relevance was also a criterion taken into account. The compound was considered to be mutagenic when there was a reproducible increase of revertants at one or more concentrations per plate in at least one strain with or without metabolic activation system respect to the negative control.

\section{Human lymphocyte chromosome aberration assay}

Chromosome aberration assay was conducted following the method described by Dean and Danford [19] following the 473 OECD guideline [20]. Two independent experiments were performed both in the presence and in the absence of activation. Whole blood samples were obtained from two healthy adult subjects (female and male for Experiments 1 and 2, respectively) in heparinized tubes. Cultures were established by placing $0.4 \mathrm{ml}$ of whole blood into $9 \mathrm{ml}$ RPMI 1640 Dutch-modified medium supplemented with $10 \%$ foetal calf serum, $50 \mu \mathrm{g} / \mathrm{ml}$ gentamycin and $5 \mu \mathrm{g} / \mathrm{ml}$ phytohaemagglutinin.

Cultures were incubated for approximately $48 \mathrm{~h}$ at $37^{\circ} \mathrm{C}$ in a $5 \%$ of $\mathrm{CO}_{2}$ environment and rocked intermittently, prior to start of treatment. Both for treatment with and without S9, quadruplicate cultures for vehicle and duplicate cultures for each test substance concentration and the positive controls were set up. Test concen- trations and conditions are detailed in $>$ Table 2 . Vehicle-control cultures were treated with DMSO and positive control cultures with EMS or CP in the absence and presence of $S 9$, respectively. In experiments 1 and 2 , cultures were treated for $24 \mathrm{~h}$ in the absence of $\mathrm{S9}$, and for $3 \mathrm{~h}$ in the presence of $\mathrm{S9}$, followed by $21 \mathrm{~h}$ recovery. In Experiment 2 an additional $48 \mathrm{~h}$ treatment in the absence of S9, and for $3 \mathrm{~h}$ treatment in the presence of $\mathrm{S} 9$ followed by $45 \mathrm{~h}$ recovery was also performed. After treatment in the presence of $\mathrm{S9}$, cells were washed twice with sterile saline and resuspended in fresh medium for completion of the recovery phase. Colcemid at a final concentration of $0.4 \mu \mathrm{g} / \mathrm{ml}$ was added $3 \mathrm{~h}$ prior to harvest. In Experiment 1 , osmolality and $\mathrm{pH}$ measurements were performed in posttreatment media both without and with S9. Cells were collected by centrifugation (10 $\mathrm{min} 600 \mathrm{~g}$ ), resuspended in hypotonic solution $(0.075 \mathrm{M} \mathrm{KCl})$ for $15 \mathrm{~min}$, and fixed in ice-cold methanol/glacial acetic acid solution $(3: 1, v / v)$. A few drops of the cell suspension were spread on microscope slides. The slides were air-dried and stained with Giemsa $5 \%$ in Sorensen buffer at pH 6.8 for 5 min. After mitotic index (MI) assessment, three test substance concentrations (with and without S9) were selected for cytogenetic analysis. For vehicle control and each test substance concentration, 200 wellspread metaphase figures were analyzed for the presence of structural chromosomal aberrations. In the case of the positive controls, 50 metaphase figures were analyzed. The classification of structural aberrations was carried out following the guidance of the International System for Cytogenetic Nomenclature (ISCN) — An International System for Human Cytogenetic Nomenclature (1985) ISCN 1985. Report of the Standing Committee on Human Cytogenetic Nomenclature, Birth Defects Orig.Artic.Ser., 21, (1985) 1-117. . The presence of polyploid, endoreduplicated and hyperdiploid cells was also recorded. For each treatment condition the proportion of cells with structural aberrations excluding gaps was compared with that of the corresponding vehicle control using Fisher's exact test [21]. The assay was considered positive (compound shown genotoxic activity) when there was a statistically significant and reproducible increase in the proportion of cells with structural aberrations (excluding gaps) at any concentration compared to the negative control and it exceeded the normal range (based on internal background historic data).

\section{Mouse lymphoma thymidine kinase assay}

The method used corresponded to the fluctuation protocol [22] following the recommendations of OECD guideline 476 [23]. The cell line employed in the experiments was the $\mathrm{L} 178 \mathrm{Y} \mathrm{TK}^{+/-}$clone3.7.2.C. Two independent experiments were performed, each conducted in the absence and presence of metabolic activation. Test concentrations for Experiment 1 were selected based on the results of a preliminary assay. Test concentrations and conditions are detailed in $>$ Table 3. Control cultures were treated with water (vehicle control), EMS or MMS (positive controls in the absence of $S 9$, to generate large and small colonies, respectively) and 3-MC (positive control in the presence of $\mathrm{S} 9$ as inducer of small colonies).

Approximately $1 \times 10^{7}$ cells were exposed in Fischer's medium supplemented with $5 \%$ horse serum, penicillin (100 units $/ \mathrm{ml}$ ), streptomycin $(100 \mu \mathrm{g} / \mathrm{ml})$, sodium bicarbonate $(1.125 \mathrm{~g} / \mathrm{ml})$, sodium pyruvate $(0.9 \mathrm{mM})$ and pluronic acid $(0.05 \% \mathrm{w} / \mathrm{v})$, to several concentrations of cizolirtine for $4 \mathrm{~h}$ at $37^{\circ} \mathrm{C}$ in a $5 \% \mathrm{CO}_{2}$ atmos- 


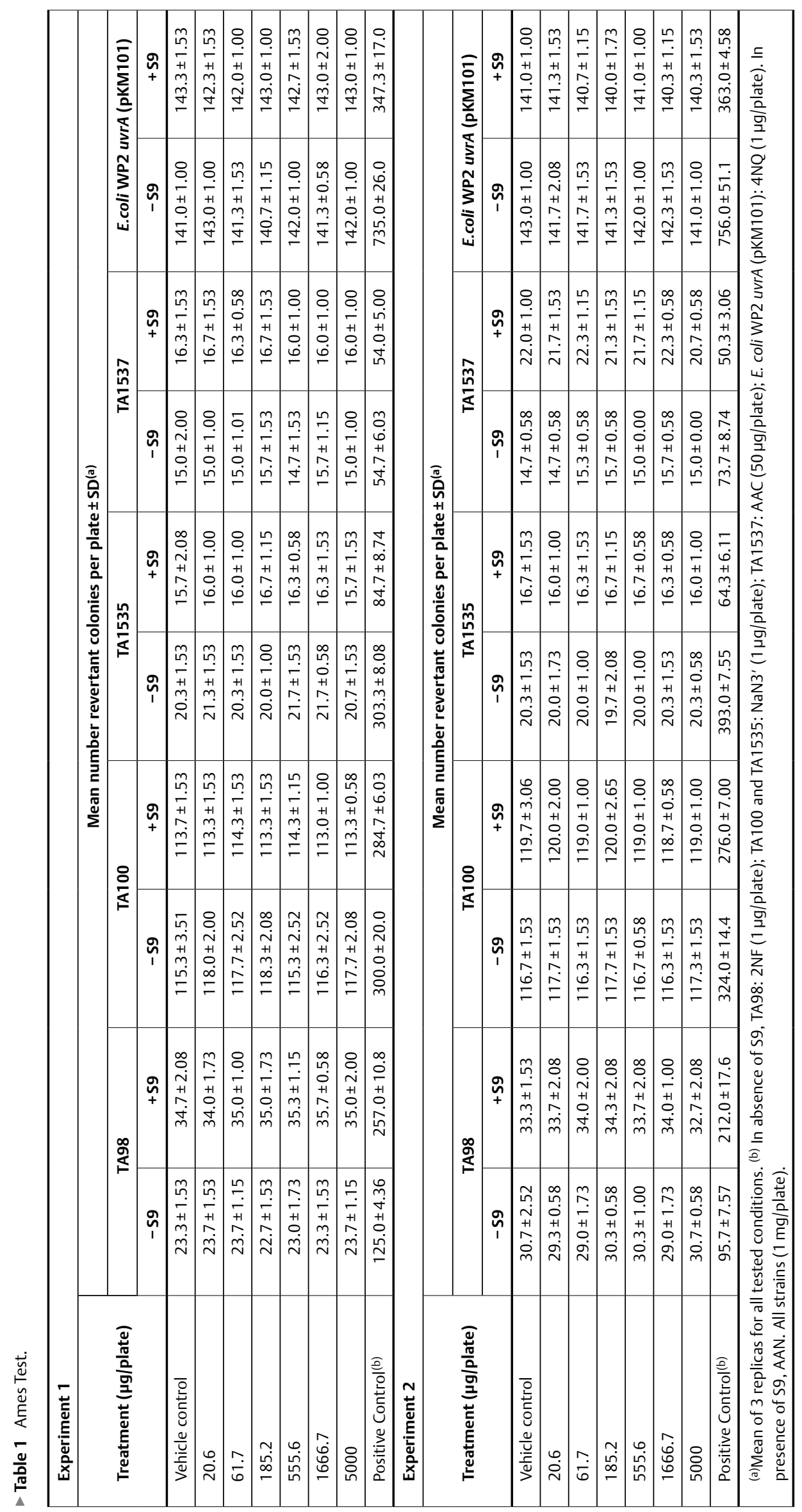




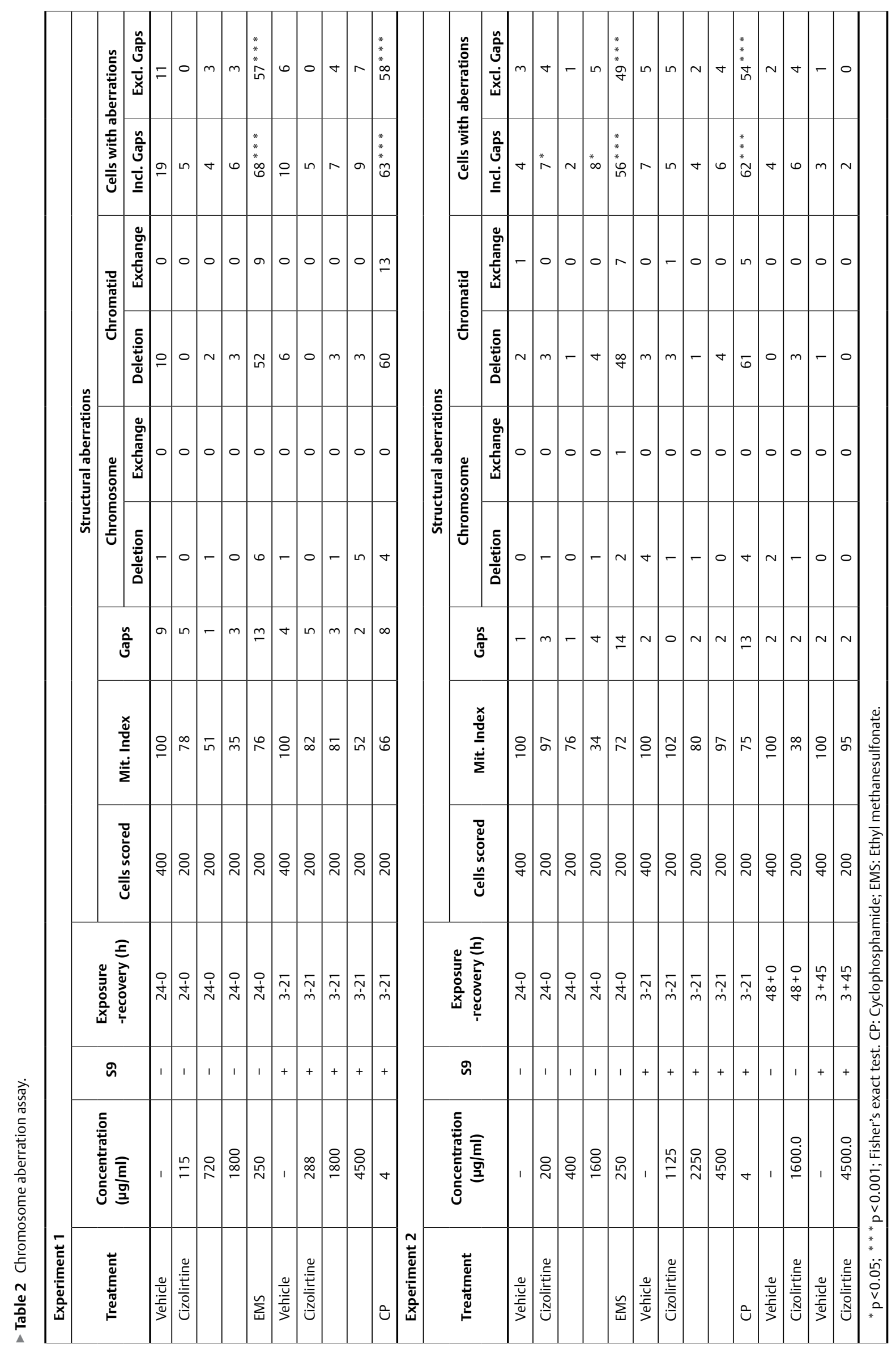




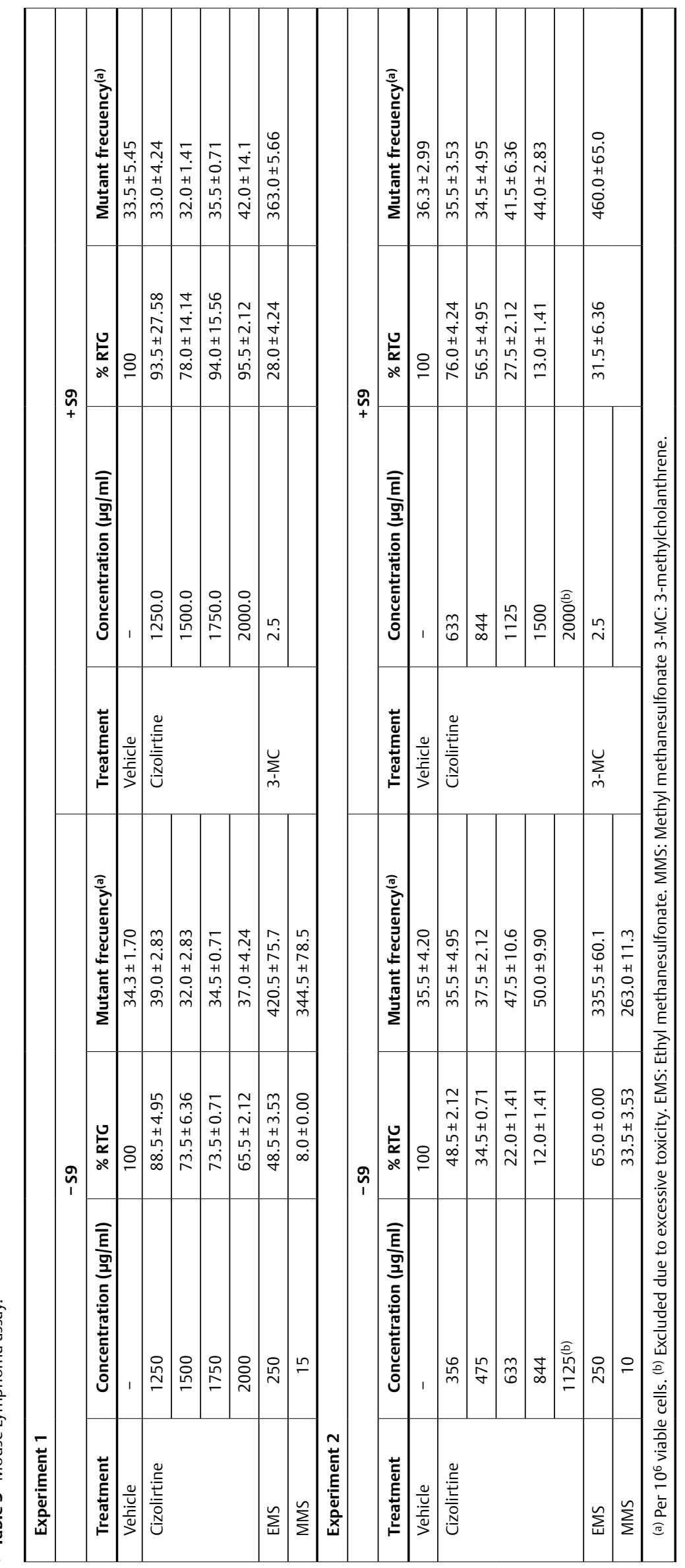


- Table 4 Mouse bone marrow micronucleus test.

\begin{tabular}{|c|c|c|c|c|c|c|}
\hline $\begin{array}{l}\text { Sampling } \\
\text { time }\end{array}$ & Treatment & $\begin{array}{l}\text { Dose } \\
(\mathrm{mg} / \mathrm{kg})\end{array}$ & $\mathbf{N}$ & $\begin{array}{l}\text { PCE/NCE } \\
(\text { mean } \pm S D)\end{array}$ & $\begin{array}{l}\text { MNPCE } / 1000 \text { PCEs } \\
(\text { mean } \pm \text { SD) }\end{array}$ & $\begin{array}{l}\text { MNNCE/1000NCEs } \\
\text { (mean } \pm \text { SD) }\end{array}$ \\
\hline \multirow{5}{*}{$24 \mathrm{~h}}$. & Vehicle & - & 10 & $1.38 \pm 0.46$ & $1.9 \pm 1.4$ & $1.8 \pm 1.5$ \\
\hline & \multirow[t]{3}{*}{ Cizolirtine } & 100 & 10 & $1.12 \pm 0.24$ & $2.9 \pm 2.1$ & $1.6 \pm 1.0$ \\
\hline & & 175 & 10 & $1.40 \pm 0.26$ & $1.8 \pm 1.9$ & $2.0 \pm 1.9$ \\
\hline & & 300 & 10 & $1.19 \pm 0.36$ & $2.2 \pm 2.3$ & $0.8 \pm 0.8$ \\
\hline & $\mathrm{CP}$ & 50 & 10 & $0.65 \pm 0.11^{* * *}$ & $28.3 \pm 10.0^{* * *}$ & $2.1 \pm 1.5$ \\
\hline \multirow{4}{*}{$48 \mathrm{~h}}$. & Vehicle & - & 10 & $1.44 \pm 0.82$ & $1.7 \pm 1.3$ & $1.0 \pm 0.7$ \\
\hline & \multirow[t]{3}{*}{ Cizolirtine } & 100 & 10 & $1.56 \pm 0.66$ & $1.1 \pm 1.1$ & $1.3 \pm 1.6$ \\
\hline & & 175 & 10 & $1.12 \pm 0.25$ & $1.1 \pm 1.5$ & $1.1 \pm 1.2$ \\
\hline & & 300 & 10 & $1.39 \pm 0.47$ & $1.8 \pm 1.6$ & $1.5 \pm 1.4$ \\
\hline \multirow{4}{*}{$72 \mathrm{~h}}$. & Vehicle & - & 10 & $1.13 \pm 0.41$ & $1.9 \pm 1.3$ & $1.6 \pm 1.6$ \\
\hline & \multirow[t]{3}{*}{ Cizolirtine } & 100 & 10 & $1.26 \pm 0.54$ & $1.8 \pm 1.2$ & $1.4 \pm 1.3$ \\
\hline & & 175 & 10 & $0.92 \pm 0.30$ & $2.2 \pm 1.5$ & $2.0 \pm 1.7$ \\
\hline & & 300 & 10 & $1.17 \pm 0.35$ & $1.5 \pm 1.8$ & $1.3 \pm 1.1$ \\
\hline
\end{tabular}

phere. Duplicate cultures were set up for the vehicle control and each test substance concentration, and single cultures for the positive control. After the $4 \mathrm{~h}$ treatment cells were washed with tissue culture medium, resuspended in $10 \%$ serum-supplemented Fischer's medium, and, when appropriate, the cell concentration was adjusted to $3 \times 10^{5} \mathrm{cells} / \mathrm{ml}$. For the viability assay, each culture was diluted to $2 \times 10^{3}$ cells $/ \mathrm{ml}$. From each culture, 3 samples of $0.1 \mathrm{ml}$ of this dilution were each added to $25 \mathrm{ml}$ of cloning medium and poured into a $90 \mathrm{~mm}$ Petri dish, so giving 200 cells per plate. For the mutant selection assay, trifluorothymidine (TFT) stock solution was added to cloning medium, to a final concentration of $3 \mu \mathrm{g} / \mathrm{ml}$. Triplicate samples of $1 \times 10^{6}$ cells each were suspended in $25 \mathrm{ml}$ cloning medium containing TFT and poured into $90 \mathrm{~mm}$ Petri dishes. Plates were incubated for 14 days at $37^{\circ} \mathrm{C}$ in a $5 \% \mathrm{CO}_{2}$ atmosphere. The colonies were then counted usually using an Artek 880 automated colony counter. If there were small colony type mutants present that were below $0.1 \mathrm{~mm}$ (size corresponding to the resolution limit of the equipment), all mutant selection plates were counted by eye. Large and small colonies were scored for vehicle, positive controls and for test substance concentrations showing a significant increase in mutant frequency. The percentage relative survival (RTG) for each treatment condition compared to the vehicle-control culture and the mutant frequency per $10^{6}$ viable cells (MF) were determined. The vehicle-control log mutant frequency was compared with that from each treatment concentration by means of the Dunnett's test [18] and checked for a linear trend by chi-square analysis, according to UKEMS guidelines [24]. The result was considered positive when the mutation frequency of any test concentration exceeded the sum of the mean control mutant frequency plus the global evaluation factor (90 mutants per $10^{6}$ viable cells for the agar version of the test [25]) and there was a statistically significant dose-response.

\section{Mouse bone marrow micronucleus test}

The micronucleus test was conducted using the method previously described by Schmid [26] following the recommendations of the
OECD 474 guideline [27]. Albino Swiss CFLP mice were supplied by Interfauna Ibérica (Sant Feliu de Codines, Spain). The animals were approximately 9-10 weeks old at the moment of administration showing a weight range of $26.7-38.9 \mathrm{~g}$ for males and $22.0-32.0 \mathrm{~g}$ for females. Animals were allocated in cages in groups of maximum 5 , separated by sex. Animals had ad libitum access to water and commercial rodent diet (Panlab S.L.). The night prior to administration of the test substance mice were kept under fasting conditions. Based on a preliminary study, dose levels of 100, 175 and $300 \mathrm{mg} / \mathrm{kg}$ of cizolirtine were selected for treatment. Groups of 15 male and 15 female animals each received either saline (vehicle) or cizolirtine at the previously mentioned doses. A positive control group of 5 males and 5 females received CP at a dose of $50 \mathrm{mg} /$ $\mathrm{kg}$. All animals were dosed by intraperitoneal route of administration (dose volume of $10 \mathrm{ml} / \mathrm{kg}$ ). Groups of 5 male and 5 female mice were sacrificed by cervical dislocation 24,48 or $72 \mathrm{~h}$ after vehicle or cizolirtine administration. Mice treated with positive control were sacrificed $24 \mathrm{~h}$ post-administration ( $\bullet$ Table 4 ). For each animal, bone marrow was extracted from dissected femurs and smears were prepared on slides containing a drop of foetal calf serum (two slides per animal). The smears were fixed with methanol before being stained with a $5 \%$ Giemsa solution. Prior examinations under light microscopy, the slides were coded to avoid any bias during the analysis. For each individual, the relative proportion of polychromatic erythrocytes (PCE) and normochromatic erythrocytes (NCE) was noted by counting a total sample of 1000 erythrocytes. On the other hand, the number of micronucleated polychromatic erythrocytes (MNPCE) per 2000 PCE was also calculated. The number of MNPCE in belonging to each treated group (either, combined or males and females separately) were compared versus the number obtained in the vehicle group using the Dunnett's test [18] after rank transformation of data. The result was considered positive when there was a statistically significant increase $(p<0.05)$ in the frequency of MNPCE, at least at one dose, that exceeded the historical vehicle control range. 


\section{Results}

\section{Ames Test}

In the two independent conducted assays, no increases in the number of revertants compared to the vehicle control were observed when cizolirtine was tested in any of the five strains composing the bacterial battery. The same result was observed in presence and absence of a rat liver metabolic activation system (S9) up to concentrations of $5000 \mu \mathrm{g} /$ plate. Results are shown in $>$ Table 1. There was neither, evidence of precipitation of cizolirtine nor signs of cytotoxicity at any of the six concentrations assayed and in any of the different assayed conditions. Positive controls employed in the assay clearly increased the number of revertants in comparison to the vehicle control. As a consequence, it was concluded that cizolirtine was not showing any genotoxic effect in this bacterial assay.

\section{Human lymphocyte chromosome aberration assay}

Human peripheral blood lymphocytes from two different donors were exposed in vitro to cizolirtine at concentrations of up to 1800 and $4500 \mu \mathrm{g} / \mathrm{ml}$ in the absence and in the presence of metabolic activation, respectively. The concentration of $4500 \mu \mathrm{g} / \mathrm{ml}$ equals to $10 \mathrm{mM}$. Results of mitotic index evaluation are shown in $>$ Table 2. In both experiments, it was observed a decrease in mitotic index with increasing concentrations of the test substance. Concentrations for metaphase analysis were selected trying to include concentrations showing an overall reduction in mitotic index.

Likewise, in both experiments, all cizolirtine-treated cultures showed a frequency of cells with chromosome aberrations excluding gaps similar to that of the vehicle control. In the second experiment, in the 24-h sampling but including gaps, the 200 and $1600 \mu \mathrm{g} / \mathrm{ml}$ concentrations in the absence of S9 showed a slight statistical increase in the frequency of cells with chromosome aberrations $(p<0.05)$, as compared to the vehicle control value. Nevertheless such increases were not considered biologically significant since they were moderate, were within the laboratory historical control values, were not observed at similar concentrations in the first assay, were not reproduced at a latter sampling time (48 $\mathrm{h}$ ) in the second assay, and did not translate into increased frequency of cells with chromosome aberrations when excluding gaps. On the other hand, ethylmethanosulphanate and cyclophosphamide caused in absence and presence of S-9 mix, respectively, statistically significant increases $(p<0.001)$ in the frequency of cells with chromosome aberrations, as compared to the vehicle control value. Overall, the results obtained allow concluding that cizolirtine shows no signs of clastogenic activity in this in vitro experimental system.

\section{Mouse Lymphoma assay}

The preliminary cytotoxicity test conducted with cizolirtine showed that this compound caused complete toxicity at a concentration of $2500 \mu \mathrm{g} / \mathrm{ml}$ when dissolved in water. Moreover, it was observed that the test compound was inducing a reduction in $\mathrm{pH}$ (noted on dosing by colour change in the phenol red indicator of the culture media), and corroborated after measuring the value at the end of the exposure period. The degree of the $\mathrm{pH}$ decrease (estimated by colour change in the phenol red indicator) indicated that the results could have been obtained at concentrations producing a $\mathrm{pH}$ shift greater than 1 unit. It has been published that $\mathrm{pH}$ shifts great- er than 1 unit can rise false positive effects [28]. To avoid this $\mathrm{pH}$ limiting factor, a second preliminary cytotoxicity test was carried out. In this occasion, cizolirtine formulation was neutralised with sodium hydroxide, showing that the compound was even more cytotoxic when neutralised. In these later tests, cizolirtine was dissolved and diluted in tissue culture medium.

Based on the preliminary tests, 4 independent mutation assays were conducted ( 2 in the absence and 2 in the presence of metabolic activation) ( $\triangleright$ Table 3 ). First and second mutation assays (Experiment 1) used concentrations of cizolirtine ranging from 1250 to $2000 \mu \mathrm{g} / \mathrm{ml}$ without $\mathrm{pH}$ neutralisation in the absence and presence of S9 mix (these concentration levels causing not significantly more than 1 unit of shift in $\mathrm{pH}$ ). Third and fourth assays (Experiment 2) were performed in neutralising conditions of $\mathrm{pH}$. More precisely, third assay used a compound range of concentrations between 356 and $844 \mu \mathrm{g} / \mathrm{ml}$ (in the absence of S9 mix) while in the presence of metabolic activation the range used was $633-1500 \mu \mathrm{g} / \mathrm{ml}$.

In the first and second mutation assays, the maximum dose levels were limited by the $\mathrm{pH}$ decrease caused by the test material (large shifts in $\mathrm{pH}$ should be avoided due to potential false positive effects). The highest concentrations in the third and fourth assays induced a reduction in the mean relative total growth (parameter equivalent to survival) to $12 \%$ and $13 \%$ in the absence and presence of S9 mix, respectively. This represents a definitive level of toxicity. Sensitivity of the experiments was proved by the well performance of both positive controls and the effectiveness of the $\$ 9$ mix. No evidence of mutagenic activity was observed in cizolirtinetreated cultures in any experimental condition tested in mouse lymphoma L5178Y cells.

\section{Bone marrow mouse micronucleus test}

Clinical signs and mortality were observed among animals treated with cizolirtine. More precisely, two male and two female animals treated with $300 \mathrm{mg} / \mathrm{kg}$ died after cizolirtine administration. These animals were replaced by animals from a supplementary group treated with the same dose. This way, data was obtained from 10 animals per group of treatment ( 5 males and 5 females). Diminished spontaneous activity was observed in all animals treated with cizolirtine, as well as tremor in intermediate- and high-dose treated animals. High-dose animals treated at $300 \mathrm{mg} / \mathrm{kg}$ also showed excitation, clonic convulsions, vocalization and slight ataxia. The first signs were detected 5 min after administration. All animals had a normal outward appearance $3 \mathrm{~h}$ after administration. Cizolirtine treated groups exhibited at all sampling time points, a MNPCE frequency similar to that of the vehicle control group ( $\triangleright$ Table 4). On the other hand, the administration of $50 \mathrm{mg} / \mathrm{kg}$ of cyclophosphamide caused a statistically significant $(P<0.001)$ increase in the MNPCE frequency with respect to the vehicle control group at $24 \mathrm{~h}$ post-administration. Likewise, samples extracted from treated groups exhibited a PCE/NCE ratio similar to that of control group. This ratio showed a statistically significant decrease $(p<0.001)$ in animals treated with cyclophosphamide. The results obtained in this in vivo test allow concluding that cizolirtine shows no evidence of genotoxic potential or cytotoxic effects on the bone-marrow of mice when administered intraperitoneally as a single dose. 


\section{Discusion}

Cizolirtine is a modulator of the release of substance $P$ and calcitonin gene-related peptide (CGRP) showing activity in the treatment of pain and urinary incontinence. As part of the preclinical safety-assessment program required by the regulatory authorities, the genotoxic potential of cizolirtine was evaluated employing a battery of in vitro and in vivo genetic toxicity assays according to the recommendations of ICH and OECD guidelines [17, 20, $23,27,29]$. This package consisted in an Ames test, a chromosome aberration assay in Human Lymphocytes, a Mouse Lymphoma gene mutation assay and a single dose mouse micronucleus assay. Cizolirtine demonstrated to be devoid of genotoxic potential in the Ames test, Mouse Lymphoma assay and the mouse bone marrow micronucleus test. In the Human Lymphocyte chromosome aberration, cizolirtine-treated cultures showed no increases in the number of cells with chromosome aberrations excluding gaps in any of the assays and any of the treatment conditions. When including gaps, a slight but statistical significant $(p<0.05)$ increase in the frequency of chromosome aberrations was observed in experiment 2 at $24 \mathrm{~h}$ in the absence of metabolic activation in the high and in the low concentrations analysed in the assay, but not in the intermediate concentration. In other words, there was not a dose related effect associated with this response. Despite this increase was statistically significant, it was within the laboratory historical control value range and more importantly, the same effect was neither observed in the analysis made at a later time point $(48 \mathrm{~h})$ in the same experiment nor under similar conditions in the experiment 1 . An important point to take in consideration is that gaps are not equivalent to chromosome breaks as they are considered non-staining regions of a single chromatid in which there is minimal misalignment of the chromatid [20], and are considered to represent spiral unravellings but not chromosome aberrations [30]. As such, and according to the current regulatory guidance, in the interpretation of chromosomal aberration study outcomes, gaps have to be recorded and reported separately but not included in the total aberration frequency [20]. Chromosomal study results are therefore $a$ priori judged based on total chromosomal aberration frequencies excluding gaps. In this respect, cizolirtine did not show any increase in total chromosomal aberration frequencies excluding gaps in any of the conducted experiments and under any of the tested conditions, and was therefore considered as non-genotoxic in this experimental system. But additionally, the lack of genotoxic effects of cizolirtine in the Mouse Lymphoma assay (that allows detecting the effect of chromosome aberrations in mammalian cells in vitro) and in the bone marrow mouse micronucleus assay (that detects chromosome aberrations in vivo) further supports that the slight increase in the frequency of chromosome aberrations including gaps observed in the Human Lymphocyte chromosome aberration assay would be lacking of biological significance.

Cizolirtine contains a diarylalkylamine chemical substructure that for a number of compounds has been linked to the potential for inducing chromosome damage [31,32]. One of these compounds is the antihistaminic drug diphenhydramine, which is a close structural analogue. Positive results have been reported for diphenhydramine in the chromosomal aberrations test in $\mathrm{CHO}$ cells in the absence of metabolic activation but not in the presence of S9 [31, 32]. However, cizolirtine show neither clastogenic nor an- eugenic activities in the chromosome aberrations test using human lymphocytes, in the mouse lymphoma assay or in the in vivo micronucleus test depicted in this genotoxicity assessment.

Taking in mind the results obtained with the whole battery of studies conducted, the conclusion reached is that cizolirtine would not pose a genotoxic risk when administered in humans.

\section{Conflict of Interest}

The authors were employees of Esteve Pharmaceuticals.

\section{References}

[1] Alvarez I, Andreu F, Buxens J et al. Pharmacology of cizolirtine: A new analgesic agent. Methods Find. Exp Clin Pharmacol 2000; 22: 211-221. doi:10.1358/mf.2000.22.4.584453

[2] Aubel B, Kayser V, Farré A et al. Evidence for adenosine- and serotonin-mediated antihyperalgesic effects of cizolirtine in rats suffering from diabetic neuropathy. Neuropharmacology 2007; 52: 487-496. doi:10.1016/j.neuropharm.2006.08.017

[3] Farre AJ, Frigola J. Cizolirtine Citrate. Drugs Future 2002; 27: 721-732. doi:10.1358/dof.2002.027.08.692100

[4] Matthew IR, Ogden GR, Frame JW et al. Dose response and safety of cizolirtine citrate (E-4018) in patients with pain following extraction of third molars. Curr Med Res Opin 2000; 16: 107-114

[5] Kayser V, Farré A, Hamon M et al. Effects of the novel analgesic, cizolirtine, in a rat model of neuropathic pain. Pain 2003; 104 : 169-177. doi:10.1016/s0304-3959(02)00497-9

[6] Aubel B, Kayser V, Mauborgne A et al. Antihyperalgesic effects of cizolirtine in diabetic rats: behavioral and biochemical studies. Pain 2004; 110. doi:10.1016/j.pain.2004.03.001

[7] Shembalkar P, Täubel ], Abadias M et al. Cizolirtine citrate (E-4018) in the treatment of chronic neuropathic pain. Curr Med Res Opin 2001; 17: 262-266

[8] Ballet S, Aubel B, Mauborgne A et al. The novel analgesic, cizolirtine, inhibits the spinal release of substance $P$ and CGRP in rats. Neuropharmacology 2001; 40: 578-589. doi:10.1016/s0028-3908(00)00186-6

[9] Montier F, Carruette A, Moussaoui S et al. Antagonism of substance $P$ and related peptides by RP 67580 and CP-96,345, at tachykinin NK1 receptor sites, in the rat urinary bladder. Eur J Pharmacol 1994; 251. doi:10.1016/0014-2999(94)90436-7

[10] Irwin DE, Mungapen L, Milsom I et al. The economic impact of overactive bladder syndrome in six Western countries. BJU Int 2009; 103: 202-209. doi:10.1111/j.1464-410X.2008.08036.x

[11] Irwin DE, Milsom I, Hunskaar S et al. Population-based survey of urinary incontinence, overactive bladder, and other lower urinary tract symptoms in five countries: Results of the EPIC study. Eur Urol 2006; 50: 1306-1314 discussion 1314-1315. doi:10.1016/j. eururo.2006.09.019

[12] Novara G, Galfano A, Secco S et al. A systematic review and metaanalysis of randomized controlled trials with antimuscarinic drugs for overactive bladder. Eur Urol 2008; 54: 740-763 . doi:10.1016/j. eururo.2008.06.080

[13] Martínez-García R, Abadías M, Arañó P et al. Cizolirtine citrate, an effective treatment for symptomatic patients with urinary incontinence secondary to overactive bladder: a pilot dose-finding study. Eur Urol 2009; 56: 184-190. doi:10.1016/j.eururo.2008.04.027 
[14] Zát'ura F, Vsetica ], Abadías M et al. Cizolirtine citrate is safe and effective for treating urinary incontinence secondary to overactive bladder: a phase 2 proof-of-concept study. Eur Urol 2010; 57 : 145-152. doi:10.1016/j.eururo.2009.04.045

[15] Parliament E, Council E. Directive 2010/63/EU on the protection of animals used for scientific purposes. EU Off J 2010; L276

[16] Maron DM, Ames BN. Revised methods for the Salmonella mutagenicity test. Mutat Res 1983; 113. doi:10.1016/0165-1161(83)90010-9

[17] OECD. (1997) Test No. 471: Bacterial Reverse Mutation Test

[18] Dunnett CW. A multiple comparison procedure for comparing several treatments with a control. J Am Stat Assoc 1955; 50: 1096-1121 Accessed 2 April 2020

[19] Dean BJ, Danford N. Assays for the detection of chemically-induced chromosome damage in cultured mammalian cells. In: Venitt, S, Parry, JM, editors. Mutagenicity Testing: A practical approach. Oxford: IRL Press; 1984: 187-232

[20] OECD. (1983) Test No. 473: In Vitro Mammalian Chromosomal Aberration Test

[21] Richardson C, Williams JA, Allen JA et al. Analysis of data from in vitro cytogenetic assays. In: Kirkland. DJ, Editor. Statistical evaluation of mutagenicity test data. UKEMS Guidelines Subcommittee Report, Part III. Cambridge University Press; 1989: 141-154

[22] Cole J, Mc Gregor DB, Fox M et al. Gene mutation assay in cultured mammalian cells. In: Kirkland. DJ, Editor. Basic mutagenicity tests UKEMS Recommended Procedures. Cambridge University Press; 1990: 87-114

[23] OECD. (2016) Test No. 476: In Vitro Mammalian Cell Gene Mutation Tests using the Hprt and xprt genes
[24] Robinson WD, Green MHL, Cole ] et al. Statistical evaluation of bacteria/mammalian fluctuation test. In: Kirkland. DJ, Editor. Statistical Evaluation of Mutagenicity Test Data. Cambridge University Press; 1990: 102-140

[25] Moore MM, Honma M, Clements ] et al. Mouse lymphoma thymidine kinase gene mutation assay: follow-up meeting of the International Workshop on Genotoxicity Testing-Aberdeen, Scotland, 2003-Assay acceptance criteria, positive controls, and data evaluation. Environ Mol Mutagen 2006; 47. doi:10.1002/em.20159

[26] Schmid W. The micronucleus test. Mutat Res 1975; 31. doi:10.1016/0165-1161(75)90058-8

[27] OECD. (2016) Test No. 474: Mammalian Erythrocyte Micronucleus Test

[28] Scott D, Galloway SM, Marshall RR et al. International Commission for Protection Against Environmental Mutagens and Carcinogens. Genotoxicity under extreme culture conditions. A report from ICPEMC Task Group 9. Mutat Res 1991; 257. doi:10.1016/01651110(91)90024-p

[29] ICH S2. (2012) Genotoxicity testing and data interpretation for pharaceuticals intended for human use

[30] Topaktaş M, Rencüzoğullar E. Chromosomal aberrations in cultured human lymphocytes treated with Marshal and its effective ingredient Carbosulfan. Mutat Res 1993; 319: 103-111. doi:10.1016/01651218(93)90068-o

[31] NTP Toxicology and Carcinogenesis Studies of Diphenhydramine Hydrochloride (CAS No. (1989). Natl Toxicol Program Tech Rep Ser, 355

[32] Snyder RD. A review and investigation into the mechanistic basis of the genotoxicity of antihistamines. Mutat Res 1998; 411: 235-248. doi:10.1016/s1383-5742(98)00016-7 